\title{
Impact of Chronic Urticaria on Quality of Life in a Tertiary Level Hospital in Nepal
}

\author{
Das AK', Paudel U², Brar N ${ }^{3}$, Karn A \\ ${ }^{1}$ Associate Professor, ${ }^{2}$ Associate Professor, ${ }^{3}$ Resident, Department of Dermatology and Venereology, Institute of \\ Medicine, Maharajgunj Medical Campus, Kathmandu, Nepal, ${ }^{4}$ Medical Officer, Nepal Mediciti Hospital, Lalitpur, Nepal.
}

\begin{abstract}
Introduction: Most healthcare providers recognize that urticaria is frequently difficult to treat but many do not realize the substantial negative impact, chronic urticarial (CU) has on patient's quality of life (QoL). The questionnaire specifically developed to measure health related quality of life in chronic urticaria is the Chronic Urticaria Quality of Life (CU-Q2oL) questionnaire. This questionnaire has helped to define the effects and impact on patients.

Objective: To assess the impact of chronic urticaria on quality of life at tertiary level hospital in Nepal.

Materials and Methods: This was a hospital based cross-sectional study conducted in the Department of Dermatology and Venereology, Tribhuvan University Teaching Hospital, Kathmandu, Nepal, over a period of one year involving 230 patients in the study. A detailed history along with the complete cutaneous examination was carried out in all patients.

Results: All the 230 patients (100\%) had symptoms of wheals and pruritus while eye swelling and lip swelling was present only in $20 \%$ and $25 \%$ respectively. Highest Mean scores were seen of pruritus (4.34) and wheals (4.29). Highest mean score was achieved by domain of pruritus (4.31) followed by domain of sleep (2.31), life activities (2.22), limits (2.05), looks (1.76) and swelling (1.4).

Conclusion: Chronic Urticaria impacts the quality of life by affecting various aspects in patient's life. CU-Q2oL questionnaire could reveal the involvement of various such aspects, which were seldom realized by the patients themselves. Patients had worst quality of life with symptoms of pruritus and wheals.

Key words: Angioedema; Chronic urticaria; Quality of life
\end{abstract}

\section{Introduction}

U ticaria is characterized by a skin lesion which consists of wheal and flare reaction in which localized intracutaneous edema is surrounded by an area of redness that is typically pruritic. Individual wheals can last as briefly as 30 minutes to as long as 36 hours. They can be as small as a millimeter or 6-8 inches in diameter. ${ }^{1}$

In angioedema, the pathology is in the deep dermis and subcutaneous tissue and swelling is the major manifestation. Urticaria is considered to be acute if

Financial disclosure: None.

Conflict of interest to disclosure: None declared.

\footnotetext{
Address of Correspondence

Dr. Anil Kumar Das

Associate Professor

Department of Dermatology and Venereology

Institute of Medicine, Maharajgunj Medical Campus,

Kathmandu, Nepal.

Email:dranildas@gmail.com
}

the duration is less than 6 weeks. Episodes of urticaria persisting beyond six weeks are considered chronic. ${ }^{1}$ It is estimated that around $40 \%$ of patients of Chronic urticaria have accompanying episodes of angioedema. ${ }^{2}$

Chronic urticaria is a common skin disease. Urticaria including angioedema affects approximately $15 \%$ of the population at some point in their lifetime. ${ }^{3}$ It is more common in females as compared to males. ${ }^{4}$

Submitted: $10^{\text {th }}$ January 2020

Accepted: $15^{\text {th }}$ February 2020

Published: $7^{\text {th }}$ October 2020

\section{How to cite this article}

Das AK, Paudel U, Brar N, Karn A. Impact of chronic urticaria on quality of life in a tertiary level hospital in Nepal. Nepal Journal of Dermatology, Venereology and Leprology 2020;18(1):52-5. https://dx.doi. org/10.3126/njdvl.v18i1.30593.

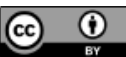

Licensed under CC BY 4.0 International License which permits use, distribution and reproduction in any medium, provided the original work is properly cited. 
Even if it is generally not life threatening, chronic urticaria is a disabling disease with important impact on health related quality of life and has a relevant socioeconomic burden. ${ }^{4}$

This study has adopted the chronic urticaria quality of life questionnaire ( $\mathrm{Cu}-\mathrm{Q} 2 \mathrm{oL})$ which is a valid instrument for the assessment of health related quality of life (HRQoL) in clinical management of chronic urticaria and for the evaluation of treatment outcome.

\section{Materials and Methods}

This study was conducted for a period of 12 months from July 2018 to June 2019. All patients more than 18 years attending the Tribhuvan University Teaching Hospital, Dermatology and Venereology Out Patient Department, clinically diagnosed with chronic urticaria were included. The participants were informed about the questionnaire and informed written consent was taken. The preformed proforma was filled prior to the test and details of patients were recorded. The questionnaire was self-administered to the patients in the Dermatology and Venereology outpatient department and patients were asked to return the questionnaire after filling it.

Descriptive analysis was used in the study. Continuous variables were expressed in frequency and percentage. Discrete variables were expressed in mean and standard deviation (SD). Data entry and analysis was conducted using SPSS version 20.

\section{Results}

A total of 230 patients were enrolled in the study out of which, $65.7 \%(n=151)$ were females and $34.5 \%$ $(n=79)$ were males.

Out of 230 patients enrolled, $100 \%$ patients had symptom of pruritus and out of this, in $53 \%$ of patients, pruritus was perceived as very much (score = 5), $29 \%$ complained of a lot (score $=4$ ) of pruritus, $17 \%$ complained of somewhat (score $=3$ ) pruritus, and only $1 \%$ complained of a little (scale $=2$ ) pruritus (Table 2 ).

Similarly, out of a total of 230 patients, $100 \%$ patients had symptom of wheals. Out of this, $47 \%$ of patients complained of very much (score $=5$ ) wheals, $38 \%$ complained of a lot (score $=4$ ) of wheals, $11 \%$ had somewhat (score $=3$ ) of wheals and $3 \%$ complained of a little (score $=2$ ) wheals (Table 2 ).

Out of 230 patients, only $20 \%$ of patients complained of swelling of eyes. Out of this $20 \%$ of patients, in $2 \%$ of patients swelling of eyes was very much (score $=5$ ), in $2 \%$ patients swelling of eyes was a lot (score $=4$ ), in $7 \%$ patients it was somewhat (score $=3$ ) and in $10 \%$ patients swelling of eyes was a little (score $=2)$. While $80 \%$ patients had no swelling of eyes at all (score $=1$ ) [Table 2].

Out of a total of 230 patients enrolled, $75 \%$ patients had no swelling of lips at all (score= 1 ), $12 \%$ had a little (score $=2$ ), 9\% had somewhat (score = 3), 3\% had a lot (score $=4$ ) and only $1 \%$ had very much (score $=5$ ) swelling of lips [Table 2].

Among the 6 domains, Pruritus had highest mean domain (4.31) followed by Sleep (2.31), Life activities (2.22), Limits (2.05), Looks (1.76), and Swelling (1.4) [table 3].

Table 1: Age group distribution of the patients

\begin{tabular}{|c|c|c|}
\hline Age & Frequency & Percent \\
\hline $18-30$ & 114 & 49.6 \\
\hline $31-45$ & 85 & 37 \\
\hline $46-60$ & 21 & 9.1 \\
\hline Above 60 & 10 & 4.3 \\
\hline Total & $\mathbf{2 3 0}$ & $\mathbf{1 0 0}$ \\
\hline
\end{tabular}

Table 2: Distribution of Effect of Symptoms in patients

\begin{tabular}{|l|c|c|c|c|}
\hline Effect of Symptoms & Pruritus & Wheals & Eye swelling & lip swelling \\
\hline Not at all (1) & $0 \%$ & $0 \%$ & $80 \%$ & $75 \%$ \\
\hline A little (2) & $1 \%$ & $3 \%$ & $10 \%$ & $12 \%$ \\
\hline Somewhat (3) & $17 \%$ & $11 \%$ & $7 \%$ & $9 \%$ \\
\hline A lot (4) & $29 \%$ & $38 \%$ & $2 \%$ & $3 \%$ \\
\hline Very much (5) & $53 \%$ & $47 \%$ & $2 \%$ & $1 \%$ \\
\hline
\end{tabular}


Table 3: Item and Domain mean

\begin{tabular}{|c|c|c|c|}
\hline Domain & Items & Item mean & Domain mean \\
\hline \multirow{2}{*}{ Pruritus } & Wheals & 4.29 & \multirow{2}{*}{4.31} \\
\hline & Pruritus & 4.34 & \\
\hline \multirow{2}{*}{ Swelling } & Eye swelling & 1.37 & \multirow{2}{*}{1.4} \\
\hline & Lip swelling & 1.44 & \\
\hline \multirow{6}{*}{ Impact on life activities } & Work & 2.59 & \multirow{6}{*}{2.22} \\
\hline & Physical activities & 2.16 & \\
\hline & Sleep interference & 2.72 & \\
\hline & Spare time & 2.18 & \\
\hline & Social relations & 1.87 & \\
\hline & Eating behavior & 1.79 & \\
\hline \multirow{5}{*}{ Sleep problems } & Falling asleep & 2.31 & \multirow{5}{*}{2.31} \\
\hline & Waking up at night & 2.33 & \\
\hline & Tired during day & 2.27 & \\
\hline & Lack of concentration & 2.06 & \\
\hline & Nervousness & 2.57 & \\
\hline \multirow{3}{*}{ Limits } & Mood & 2.90 & \multirow{3}{*}{2.05} \\
\hline & Choosing food & 1.74 & \\
\hline & Sport activities & 1.51 & \\
\hline \multirow{5}{*}{ Looks } & Side effects & 1.77 & \multirow{5}{*}{1.76} \\
\hline & Embarrassed & 2.00 & \\
\hline & Avoiding public places & 1.98 & \\
\hline & Cosmetics & 1.43 & \\
\hline & Clothing material & 1.62 & \\
\hline
\end{tabular}

\section{Discussion}

$\mathrm{CU}$ seriously compromises the HRQoL of patients due to debilitating and uncomfortable symptoms that may last for years. ${ }^{7}$ In addition to classic symptoms like pruritus and papules, other factors are more relevant for patients with chronic urticaria, such as unpredictability of flares, sleep disorders, fatigue, drug-related side effects, and physical appearance. Thus, merely evaluating urticaria progress by counting lesions and measuring pruritus intensity is insufficient. A holistic evaluation of the patient is required for a better understanding of disease impact. ${ }^{6}$

$\mathrm{CU}-\mathrm{Q}_{2} \mathrm{OL}$ is a valid and specific instrument to evaluate the HRQoL and is easily applied..$^{5}$ This study aims to evaluate the impact of chronic urticaria on the quality of life of patients in a tertiary level hospital.

In this study among 230 patients, the most commonly involved age group was between 18 and 30 years with a mean age of $33 \pm 12.8$ years. It was similar to a study done by Gowda et al in which mean age was $35 \pm 11.7$ years. $^{8}$ In study done by Pherwani et al, the mean age of patients was $38 \pm 10.2$ years. ${ }^{9}$ In an another study done by Heng et al, the mean age of patients was $43.18 \pm 24$ years. ${ }^{10}$ In most studies, the peak age of CU occurrence is between 20 and 40 years. ${ }^{11}$ Thus, patients were mainly affected during their working life years and are were prone to absenteeism and decreased productivity because of illness and its treatment. $^{12}$

Regarding gender in our study, female preponderance was seen with 151 (65.7\%) females. Similarly, in a study done by Baiardini et al, majority of the patients were female (61.84\%). ${ }^{5}$ Also, in study done by Dias et al, female preponderance was seen with $85.72 \%$ females. ${ }^{12}$ Women likely had more sensitive skin and mental awareness toward the symptoms of hives and were more influenced by changes in appearance. ${ }^{12}$

All the 230 patients (100\%) in our study had symptoms of wheals and pruritus while eye swelling and lip swelling was present only in $20 \%$ and $25 \%$ of the patients respectively. Highest mean scores were seen for the items of pruritus (4.34) and wheals (4.29) depicting the worst quality of life in these items. Similarly, in a study done by Pherwani et al, highest scores were seen for items of pruritus and wheals. ${ }^{9}$ Also in study done by Gowda et al, highest mean score was seen for items of pruritus and wheals, thus indicating the worst quality of life in these items. ${ }^{8}$ 
In this study, majority $(74.8 \%)$ of the patients experienced interference in their work. More than half $(54.8 \%)$ of the patients had interference in their physical activity. Majority (74.3\%) of the patients had interference in their sleep. More than half (68.3\%) of the patients experienced interference in their spare time. Almost half $(48.7 \%)$ of the patients had interference in their social relationships and $37 \%$ of the patients had interference in their eating behavior because of chronic urticaria. Life activities had a domain mean of 2.22. In our study, patients had worst quality of life in domains of pruritus followed by domain of sleep, domain of life activities, domain of limits, domain of looks and domain of swelling as compared to study done by Gowda et al, where worst quality of life was seen in domains of symptoms followed by domain of life activities, domain of sleep, domain of limits, domain of looks and domain of swelling. ${ }^{8}$

\section{References}

1. Kaplan AP. Urticaria and Angioedema. In : Wolff $K$, Goldsmith L, Katz S, Gilchrest B, Paller AS, Leffell D, editors. Fitzpatrick's Dermatology in General Medicine, 8th Edition. New York: McGraw-Hill; 2011. p. 414-30.

2. Kaplan AP. Chronic urticaria: Pathogenesis and treatment. J Allergy Clin Immunol. 2004 Sep;114(3):465-74. https://dx.doi. org/10.1016/j. jaci.2004.02.049

3. Champion RH, Roberts SOB, Carpenter RG, Roger $\mathrm{JH}$. Urticaria and angio-oedema: A review of 554 patients. Br J Dermatol. 1969 Aug;81(8):588-97. https://dx.doi. org/10.1111/j.1365-2133.1969. tb16041.x

4. Lapi F, Cassano N, Pegoraro V, Cataldo N., Heiman F, Cricelli I, et al. Epidemiology of chronic spontaneous urticaria: Results from a nationwide, population-based study in Italy. Br J Dermatol. 2016 May;174(5):996-1004. https://dx.doi. org/10.1111/bjd.14470

5. Baiardini I, Pasquali $M$, Braido F, Fumagalli $F$, Guerra L, Compalati E, et al. A new tool to evaluate the impact of chronic urticaria on quality of life: Chronic urticaria quality of life questionnaire (CU-Q2oL). Allergy Eur J Allergy Clin Immunol. 2005;60(8):1073-8. https://dx.doi. org/10.1111/ j.1398-9995.2005.00833.x

6. Dias GAC, Coelho FC, Pennaforte C, Caputo F, Arraes, ACN, Pedrazzi DL, et al. Quality of life and disease activity assessment in patients with chronic urticaria. World Allergy Organ J. 2015;8:A91. https://dx.doi. org/10.1186/19394551-8-s1-a91

\section{Conclusion}

This study showed that all the patients had symptoms of wheals and pruritus while eye swelling and lip swelling was present only in $20 \%$ and $25 \%$ of the patients respectively. Highest Mean scores were seen for the items of pruritus (4.34) and wheals (4.29) indicating the worst quality of life in this domain.

Thus, CU-Q2oL could reveal the involvement of a number of items seldom realized by the patients themselves. Also, QOL assessment is the most important measure of disease severity because reductions in QOL define the patient's actual experience of living with the illness. CU-Q2oL has the ability to detect changes in QoL impairment over time and can be used for the evaluation of disease course and treatment in follow up visits.

7. Baiardini I, Giardini A, Pasquali M, Dignetti $P$, Guerra L, Specchia C, et al. Quality of life and patients' satisfaction in chronic urticaria and respiratory allergy. Allergy Eur J Allergy Clin Immunol. 2003;58(7):621-3. https://dx.doi. org/10.1034/j.1398-9995.2003.00091.x

8. Gowda G, Athani SB. A descriptive study on quality of life, depression and anxiety in chronic urticaria patients attending a tertiary care hospital in Bengaluru, South India. Int J Community Med Public Heal. 2019;6(7):3118. https://dx.doi. org/10.18203/2394-6040.ijcmph20192861

9. Pherwani AV, Bansode G, Gadhia S. The impact of chronic urticaria on the quality of life in Indian patients. Indian J Dermatol. 2012;57(2):110-3. https://dx.doi. org/10.4103/0019-5154.94277

10. Heng JK, Koh LJ, Toh MPHS, Aw DCW. A study of treatment adherence and quality of life among adults with chronic urticaria in Singapore. Asia Pac Allergy. 2015;5(4):197. https://dx.doi. org/10.5415/apallergy.2015.5.4.197

11. Maurer M, Weller K, Bindslev-Jensen C, GiménezArnau A, Bousquet PJ, Bousquet J, et al. Unmet clinical needs in chronic spontaneous urticaria. A GA2LEN task force report. Allergy Eur J Allergy Clin Immunol. 2011;66(3):317-30. https://dx.doi. org/10.1111/j.1398-9995.2010.02496.x

12. Dias GAC, Pires GV, Valle SOR, Dortas Junior $S D$, Levy S, França AT, et al Impact of chronic urticaria on the quality of life of patients followed up at a university hospital. An Bras Dermatol. 2016;91(6):754-9. https://dx.doi. org/10.1590/ abd1806-4841.20165071 